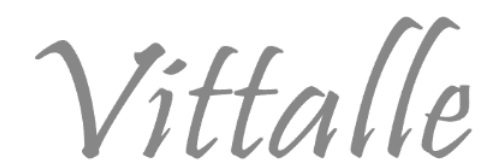

\title{
Esteroides anabolizantes androgênicos: conscientização sobre uso indiscriminado, utilização na terapêutica e relação risco-benefício
}

\author{
Beatriz Vieira Castilho ${ }^{a}$, Luciana Pereira Ruela ${ }^{\mathrm{a}}$, Luisa Marciano Grassellia, Yasmin \\ Teixeira Nunes ${ }^{\mathrm{a}}$, Cláudio Daniel Cerdeira ${ }^{\mathrm{b} *}$, Gérsika Bitencourt Santos ${ }^{\mathrm{a}}$, Alexandre \\ Ponciano $^{\mathrm{a}}$
}

${ }^{a}$ Faculdade de Medicina, Universidade José do Rosário Vellano/ UNIFENAS, Alfenas, MG, Brasil ${ }^{\text {b}}$ Departamento de Bioquímica (DBq), Instituto de Ciências Biomédicas (ICB), Universidade Federal de Alfenas -

UNIFAL, Alfenas, MG, Brasil

\section{Histórico do Artigo \\ Recebido em:}

$11 / 03 / 2021$

Aceito em:

$29 / 09 / 2021$

\section{Palavras-chave:}

Esteroides anabolizantes androgênicos; terapêutica; efeitos colaterais
Keywords:

Androgenic anabolic steroids; therapy; side effects

\begin{abstract}
RESUMO
Os Esteroides Anabolizantes Androgênicos (EAA), derivados do hormônio testosterona, apresentam importantes efeitos positivos na terapêutica. Contudo, os efeitos deletérios advindos do uso indiscriminado são atualmente agravado pelo apelo da perfeição estética que tais substâncias supostamente traz, além de, um alto rendimento em esportes e atividades como a musculação, fazendo com que a população em geral negligencie seus riscos que podem gerar sérios agravos de saúde, inclusive óbito. Neste contexto, esta revisão traz uma análise de estudos disponíveis em diferentes bases de dados, que abordam quando e em que condições o uso seguro de EAA é aconselhado na prática médica, pesando-se à relação risco-benefício. Observamos nesta revisão que, quando utilizados em doses terapêuticas e com monitoramento por profissionais de saúde, além de serem úteis no tratamento de distúrbios de puberdade, os EAA também podem ser benéficos durante o tratamento de diversas patologias, incluindo distrofia muscular, sarcopenia, falência da medula óssea, mielofibrose e doença renal crônica, bem como é relatado que eles podem auxiliar na recuperação funcional de pacientes que necessitam de ventilação mecânica ou com permanência prolongada em unidades de terapia intensiva e períodos pós operatório. Por outro lado, o uso de EAA sem acompanhamento/prescrição e indiscriminado pode causar desde sintomas agudos, tais como: euforia, irritabilidade, hiperatividade, tensão nervosa e psicose; até a consequências mais graves associadas a exposições prolongadas e crônicas, incluindo: danos no sistema cardiovascular, hipertensão, hipertrofia no ventrículo esquerdo, arritmias, trombose e pressão diastólica alterada, nestes casos, elevando o risco de morte. Diante disto, são necessárias políticas públicas de saúde para promoção de uma maior conscientização por parte de profissionais de saúde e população em geral (principalmente praticantes de musculação), instituindo práticas que permitam o entendimento do contexto no qual esta classe terapêutica é apropriada, desde que sérios riscos à saúde associados ao uso indiscriminado destes disruptores endócrinos é relacionado à consideráveis taxas de morbidade e mortalidade.
\end{abstract}

Androgenic anabolic steroids: awareness of indiscriminate use, use in therapy and riskbenefit ratio

\begin{abstract}
Anabolic-androgenic steroids (AAE) are molecules derived from the hormone testosterone. AAE have important positive effects in the treatment of different diseases. However, the harmful effects arising from the indiscriminate use of AAE is currently aggravated by the appeal of the aesthetic perfection that these substances are supposed to bring, making the general population to neglect its risks that can lead to serious health problems, including death. In this context, this review brings an analysis of studies available in different databases, which address when and under what conditions the safe use of AAE is advised in medical practice, weighing the associated risk-benefit ratio. Since used in therapeutic doses and monitored by health professionals, besides being useful for treating puberty disturbances, AAE can also be beneficial during the treatment of various pathologies, including muscular dystrophy, sarcopenia, bone marrow failure, myelofibrosis, chronic kidney disease, as well as recovering functionality in patients who need for mechanical ventilation or those ones with prolonged stay in intensive care units and in postoperative periods. On the other hand, there is a need for public health policies to promote greater awareness by health professionals and the population in general (mainly bodybuilders), instituting practices that allow an understanding of the context in which this therapeutic class is appropriate, since serious health risks associated with the indiscriminate use of these endocrine disruptors is related to considerable rates of morbidity and mortality.
\end{abstract}

\footnotetext{
*Autor correspondente: daniel.cerdeira.84@gmail.com (Cerdeira C. D.)
} 


\section{Introdução}

Os Esteroides Anabolizantes Androgênicos (EAA) são moléculas derivadas ou sintéticas análogas do hormônio testosterona. O consumo de EAA produz efeitos anabólicos com aumento de massa muscular (síntese de tecido magro) e efeitos androgênicos que promovem um incremento das características secundárias masculinas, tais como mudança do timbre de voz e aparecimento de pelos. O uso de anabolizantes se popularizou na sociedade moderna, não apenas para fins terapêuticos, mas também para fins estéticos e esportivos, em que os usuários utilizam essas substâncias de forma indiscriminada buscando atingir o corpo perfeito, conceito que pode variar de acordo com a perspectiva socioantropológica, além de um melhor rendimento atlético (1).

$\mathrm{Na}$ Medicina, o uso terapêutico de EAA pode apresentar comprovados benefícios em pacientes vivendo com HIV, pacientes que apresentam doenças crônico-degenerativas, tais como as sarcopenias, osteoporose, hipotrofia muscular e falências renal ou hepática, pacientes com hipogonadismo e câncer de mama, além do uso para tratar alterações de desenvolvimento das características sexuais secundárias na puberdade e alterações neonatal do aparelho reprodutor. O uso clínico de EAA pode ser também recomendado, por conta de seu efeito anabólico, em pacientes com politraumatismos, queimaduras e na recuperação de pacientes em períodos pós-operatórios (2).

Contudo, o uso indiscriminado de EAA, atualmente comum entre a população por conta de finalidades estéticas, bem como o uso indiscriminado entre praticantes de esportes de alto rendimento e até mesmo entre praticantes de musculação, ocasiona uma série de graves efeitos colaterais que podem ser reversíveis ou até mesmo irreversíveis. Alguns efeitos são conhecidos, como as cardiomiopatias, infertilidade e hepatotoxicidade, podendo até mesmo ocasionar morte em caso de uso inadequado e em pacientes considerados de risco (3). O uso de EAA na clínica médica é valioso, entretanto, destacase a utilização com prescrição e de maneira racional e, até mesmo neste contexto, esta classe terapêutica é considerada de risco, uma vez que os EAA exógenos são conhecidos agentes disruptores endócrinos (4).

Dessa forma, quando os EAA são utilizados de forma inadequada, normalmente associado ao apelo da perfeição estética, e em doses acima das indicadas, serão acarretados diversos efeitos colaterais indesejados com sérios riscos à saúde ou até mesmo morte. Sendo assim, este estudo buscou demonstrar os benefícios dos EAA, mas quando administrados racionalmente na prática médica, em doses corretas e com acompanhamento de profissionais de saúde.

\section{Metodologia}

Este estudo trata-se de uma revisão sistemática da literatura, abordando bases de dados de domínio público, que comparou os diferentes dados sobre os EAA, benefícios e malefícios, com questões norteadoras tais como: "Qual o conhecimento/prática sobre o uso aconselhado por profissionais e terapêuticos dos EAA?"; Qual o conhecimento/prática sobre o uso indiscriminado de EAA e não aconselhado por profissionais de saúde e os riscos à saúde? O levantamento dos artigos foi feito por meio de busca nas bases de dados: Scientific Eletronic Library Online (SciELO), Biblioteca Virtual em Saúde (BVS), MEDLINE, portal de periódicos CAPES. Para seleção desses artigos foram adotados os seguintes critérios de inclusão, também resumidos na Figura 1: artigos com textos completos disponíveis para análise; aqueles publicados nos idiomas português, inglês e/ou espanhol e em qualquer ano quanto a data de publicação, com o interstício de busca entre 2018-2020; artigos que continham em seus títulos e/ou resumos 
a combinação dos seguintes descritores reconhecidos (ou seus equivalentes em inglês): anabolizantes, esteroides anabolizantes, benefícios, uso terapêutico. Além disso, como critérios de exclusão, não foram considerados monografias, TCC, resenha, artigos de revisão, artigos de atualização ou qualquer artigo que não possuíssem os descritores supracitados e/ou estavam incompletos.

\section{Discussão}

Após o levantamento preliminar, foi possível identificar 104 estudos. Com refinamento e leitura de cada texto, na sequência foram selecionados 15 artigos para confecção dessa revisão (Figura 1). Os artigos escolhidos abordam assuntos que incluem os benefícios e riscos dos esteroides anabolizantes.

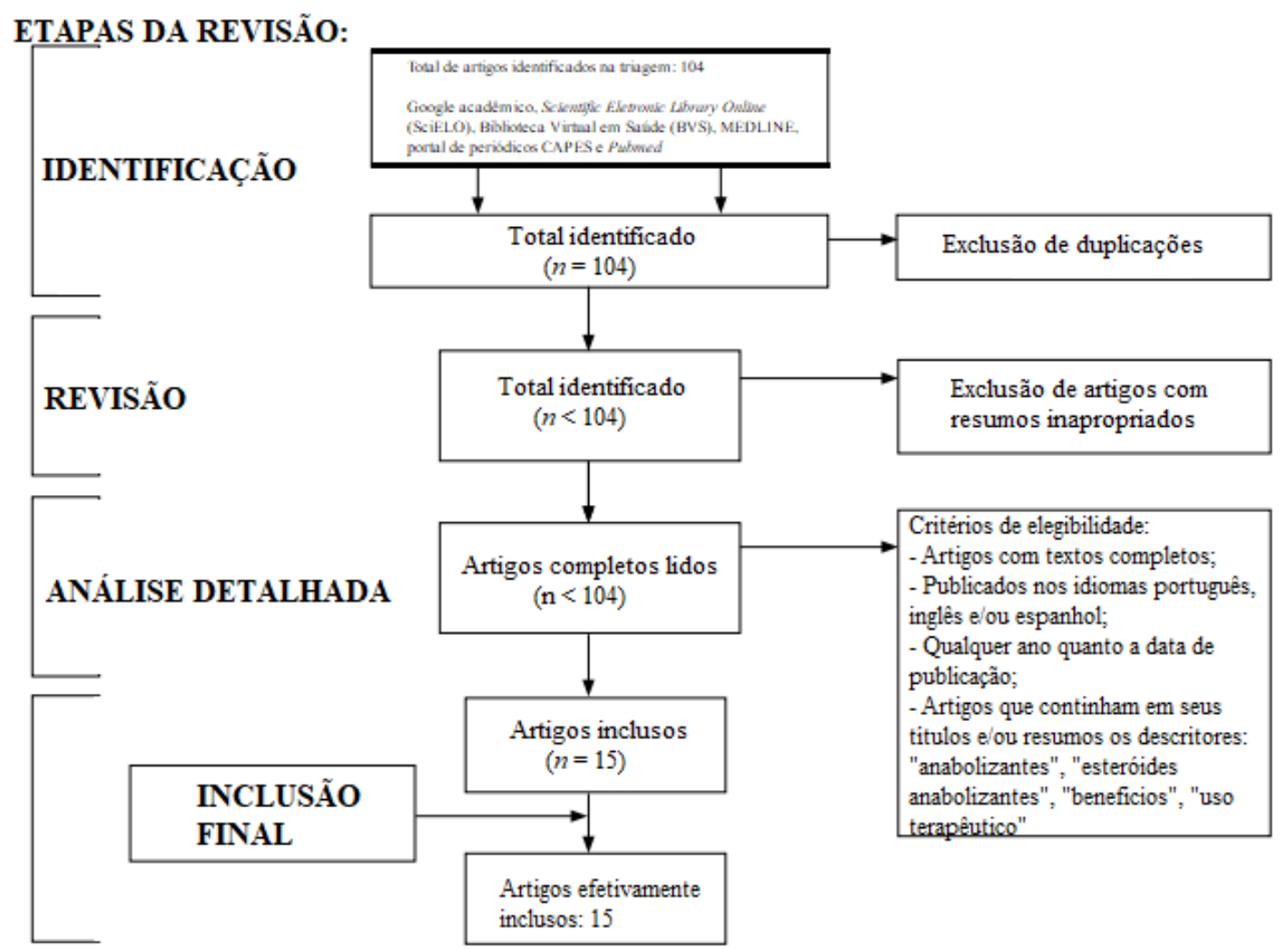

Figura 1 - Etapas e critérios da revisão.

Como resultado deste estudo destaca-se que os EAA, quando utilizados em superdosagem e/ou de forma indiscriminada acarreta efeitos prejudiciais à saúde (5-7), mas que quando são usados de forma orientada por profissionais de saúde, durante a terapêutica de certas condições médicas, e com doses controladas, eles podem trazer vários efeitos positivos (8-10).

Entre os efeitos positivos é possível citar, por exemplo, a sua utilização associada a fisioterapia para o desmame da ventilação mecânica em crianças com disfunção ventilatória. Foi observado que crianças que necessitaram de ventilação mecânica e permanência prolongada em unidades de terapia intensiva (UTIs) apresentavam complicações como "redução da massa muscular por inatividade física, resposta cardiovascular ao estresse, desmineralização óssea, perda proteica, diminuição da água corpórea total". Até o momento, os EAA mostraram ser efetivos nesses casos ao facilitar 
a retirada da ventilação mecânica e ainda ajudando no ganho de força e resistência das crianças estudadas (8).

Ainda se tratando de efeitos benéficos, conforme observado por Godoy et al. (9), há uma melhora da funcionalidade motora em idosos sarcopênicos após a utilização de EAA. Com o envelhecimento, os idosos apresentam uma perda significativa de força muscular que se deve ao fato de haver uma perda de unidades e fibras motoras. Idosos tratados com EAA, com acompanhamento e prescrição médica, demonstraram uma melhora efetiva da sarcopenia causando um aumento da massa e força muscular.

A literatura aborda que os EAA estimulam a síntese de eritropoiese e, por conta disso, podem auxiliar no tratamento da anemia por falência da medula óssea, mielofibrose ou doença renal ou hepática crônica. Os EAA também auxiliam no tratamento de insuficiência renal aguda e osteoporose, sendo que no primeiro caso, possivelmente por conta de uma diminuição na produção de uréia; e, no segundo, devido a um aumento na produção de osteoblastos que são responsáveis pela deposição de tecido ósseo (2).

Em relação aos riscos à saúde e efeitos colaterais causados pelos EAA, quando utilizados de forma inadequada e indiscriminada, um hábito comum entre praticantes de musculação e aqueles que buscam a perfeição estética (11-15), é possível citar sintomas agudos como euforia, irritabilidade, hiperatividade, tensão nervosa e psicose. De maneira mais grave, como danos associados a exposições prolongadas e crônicas, no sistema cardiovascular, os EAA podem causar hipertensão, hipertrofia no ventrículo esquerdo, arritmias, trombose e pressão diastólica alterada, o que pode elevar o risco de morte (5). Pode ocorrer também a inibição da síntese de glicose, transtorno dismórfico corporal e uma diminuição da concentração sérica dos hormônios T3 e T4, como resultados deletérios da utilização inadequada desses esteroides anabolizantes. De acordo com Nunes et al. (16), alterações estruturais e funcionais da musculatura cardíaca podem ocorrer como consequência do uso indiscriminado e toxicidade dos EAA (decanoato de nandrolona), e estes compostos podem causar danos (possível fibrose extensa e necrose) no coração e assim induzir ou agravar patologias cardíacas, seja por efeitos diretos, gerados pela ação hormonal interagindo com seu receptor androgênico e promovendo em última análise aumento do tecido (hipertrofia acentuada nas células do miocárdio), ou indiretos, relacionados não necessariamente a interação com o receptor, mas com interações adicionais com outros receptores e efeitos pleiotrópicos dos EAA (bloqueio de degradação de proteínas, por exemplo).

Por fim, são necessários novos estudos que possam complementar nosso entendimento sobre a segurança e tolerabilidade individual para os EAA, reduzindo-se assim seus efeitos colaterais. Ressalta-se que, quando utilizados de forma correta, em doses controladas e com o acompanhamento médico, os benefícios podem se sobrepor aos efeitos deletérios na terapêutica, como visto nesta revisão. Não obstante, os riscos associados ao uso não orientado e indiscriminado pode comprometer a saúde e elevar a mortalidade associada, no qual a busca pelo corpo ideal e melhor desempenho esportivo consolidam-se como as principais causas de tal uso (11-15). A Tabela 1 complementa e sumariza os achados desta revisão, quanto ao uso e indicações terapêuticas dos EAA, conscientização sobre o uso, riscos à saúde, bem como os efeitos colaterais mais comum. 
Tabela 1 - Artigos adotados na confecção desta revisão abordando a conscientização de entrevistados, os benefícios e efeitos colaterais do uso de Esteroides Anabolizantes

Androgênicos (EAA)

\begin{tabular}{|c|c|c|c|}
\hline AUTOR & ANO & OBJETIVO DO ESTUDO & $\begin{array}{l}\text { PRINCIPAIS ACHADOS } \\
\text { (RISCO-BENEFICIO) }\end{array}$ \\
\hline \multicolumn{4}{|c|}{ EFEITOS COLATERAIS/RISCOS A SAÚDE NO USO DE EAA } \\
\hline $\begin{array}{l}\text { Venâncio, Daniel et } \\
\text { al. }\end{array}$ & 2010 & $\begin{array}{l}\text { Avaliar o eixo hipófise-gonadal, a } \\
\text { função hormonal, as transaminases } \\
\text { hepáticas e o perfil de hemograma de } \\
\text { voluntários distribuídos em três } \\
\text { grupos: usuários de EAA praticantes } \\
\text { de exercício físico resistido, } \\
\text { praticantes de exercício resistido sem } \\
\text { uso de EAA e sedentários. }\end{array}$ & $\begin{array}{l}\text { Foi observado uma elevação do nível de } \\
\text { creatina quinase nos dois grupos de } \\
\text { indivíduos que se exercitavam de maneira } \\
\text { resistida, em relação ao grupo de } \\
\text { sedentários. Redução das gonadotrofinas } \\
\text { LH e FSH do grupo de usuários de EAA e } \\
\text { elevação do nível de estradiol, em } \\
\text { comparação ao grupo sedentário e treinado } \\
\text { que não usa EAA. Ainda, foi observada } \\
\text { redução da fração HDL do colesterol, em } \\
\text { relação aos dois grupos estudados. }\end{array}$ \\
\hline $\begin{array}{l}\text { Freitas, Ariane } \\
\text { Cristine et al. }\end{array}$ & 2017 & $\begin{array}{l}\text { Estudar a perda neuronal causada } \\
\text { pelo uso e abuso de EAA em } \\
\text { camundongos }\end{array}$ & $\begin{array}{l}\text { O uso inadequado e sem orientação médica } \\
\text { de EAA pode levar a degenerações } \\
\text { celulares. }\end{array}$ \\
\hline $\begin{array}{l}\text { Rocha, Fernando } \\
\text { Lima et al. }\end{array}$ & 2007 & $\begin{array}{l}\text { Investigar os possíveis efeitos } \\
\text { deletérios do uso indiscriminado de } \\
\text { EAA ao sistema cardiovascular. }\end{array}$ & $\begin{array}{l}\mathrm{O} \text { uso indiscriminado destas substâncias } \\
\text { pode aumentar o risco de morte. }\end{array}$ \\
\hline $\begin{array}{l}\text { Nunes, Ana Camila } \\
\text { Campelo de } \\
\text { Albuquerque et al. }\end{array}$ & 2020 & $\begin{array}{l}\text { Revisão dos efeitos do uso } \\
\text { indiscriminado dos EAA sobre o } \\
\text { sistema cardiovascular. }\end{array}$ & $\begin{array}{l}\text { A literatura destaca os efeitos tóxicos e } \\
\text { deletérios dos EAA sobre o sistema } \\
\text { cardiovascular, por ação direta ou indireta, } \\
\text { causando ou agravando patologias } \\
\text { cardíacas. }\end{array}$ \\
\hline \multicolumn{4}{|c|}{ USO TERAPÊUTICO DE EAA } \\
\hline $\begin{array}{l}\text { Cunha, Tatiana } \\
\text { Sousa et al. }\end{array}$ & 2004 & $\begin{array}{l}\text { Compilar os dados a respeito dos } \\
\text { EAA, envolvendo as perspectivas } \\
\text { históricas acerca do tema, a fisiologia } \\
\text { e os tipos de EAA atualmente } \\
\text { existentes, suas indicações } \\
\text { terapêuticas e efeitos adversos } \\
\text { resultantes do uso indiscriminado } \\
\text { bem como a relação entre o uso de } \\
\text { EAA e melhora do desempenho } \\
\text { atlético. }\end{array}$ & $\begin{array}{l}\text { Apesar das inúmeras lacunas a respeito da } \\
\text { comprovação de ações favoráveis dos EAA } \\
\text { sobre o desempenho atlético e do grande } \\
\text { número de seus efeitos colaterais, verifica- } \\
\text { se que o abuso de tais substâncias é uma } \\
\text { prática bastante difundida, tanto pela } \\
\text { facilidade de obtenção das mesmas por } \\
\text { meios legais ou ilegais como também pela } \\
\text { desinformação dos usuários acerca dos } \\
\text { reais riscos à saúde. } \\
\text { Terapeuticamente, são observados uso para } \\
\text { tratar patologias tais como insuficiência } \\
\text { renal aguda e osteoporose. }\end{array}$ \\
\hline $\begin{array}{lc}\text { Franz, } & \text { Flávia \& } \\
\text { Garcia, } & \text { Pedro } \\
\text { Celiny Ramos }\end{array}$ & 2010 & $\begin{array}{l}\text { Avaliar o uso de EAA associado à } \\
\text { fisioterapia pode auxiliar no ganho de } \\
\text { força e resistência, facilitando o } \\
\text { desmame da ventilação mecânica, } \\
\text { diminuindo o tempo de permanência } \\
\text { em unidade de tratamento intensivo e } \\
\text { consequentemente o tempo de } \\
\text { internação hospitalar, os quais } \\
\text { poderiam ser seus efeitos futuros. }\end{array}$ & $\begin{array}{l}\text { Até o momento, os resultados mostram que } \\
\text { o EAA como adjuvante da fisioterapia pode } \\
\text { facilitar o desmame e o ganho de força e } \\
\text { resistência muscular em crianças que } \\
\text { permaneceram muito tempo em ventilação } \\
\text { mecânica. }\end{array}$ \\
\hline $\begin{array}{l}\text { Godoy, Isabela et } \\
\text { al. }\end{array}$ & 2017 & $\begin{array}{l}\text { Correlacionar o envelhecimento com } \\
\text { a sarcopenia e a utilização de EAA } \\
\text { para controle desse quadro } \\
\text { verificando segurança e eficácia. }\end{array}$ & $\begin{array}{l}\text { Há uma capacidade de aumento da } \\
\text { hipertrofia muscular esquelética com o uso } \\
\text { de EAA e assim o indivíduo readquire } \\
\text { funcionalidade. }\end{array}$ \\
\hline
\end{tabular}


continuação

\begin{tabular}{|c|c|c|c|}
\hline $\begin{array}{l}\text { González-Martí, } \\
\text { Irene et al. }\end{array}$ & 2018 & $\begin{array}{l}\text { Conhecer a prevalência do uso de } \\
\text { esteroides anabolizantes em uma } \\
\text { amostra espanhola afetada por } \\
\text { dismorfia muscular. }\end{array}$ & $\begin{array}{l}\text { Há uma alta detecção do uso de EAA entre } \\
\text { indivíduos espanhóis que sofrem de } \\
\text { dismorfia muscular atingindo até } 47 \% \text { em } \\
\text { mulheres e } 44 \% \text { em homens. }\end{array}$ \\
\hline \multicolumn{4}{|c|}{ CONSCIENTIZAÇÃO DA POPULAÇÃO SOBRE O USO DE EAA } \\
\hline $\begin{array}{l}\text { Iriart, Jorge Alberto } \\
\text { et al. }\end{array}$ & 2009 & $\begin{array}{l}\text { Investigar as motivações para a } \\
\text { prática da musculação e para o uso de } \\
\text { anabolizantes, assim como as } \\
\text { representações e usos sociais do } \\
\text { corpo entre usuários de anabolizantes } \\
\text { que praticam musculação }\end{array}$ & $\begin{array}{l}\text { A principal razão para a prática da } \\
\text { musculação e para o consumo de } \\
\text { anabolizantes, tanto entre usuários de } \\
\text { classe média como das classes populares, é } \\
\text { a motivação estética. }\end{array}$ \\
\hline $\begin{array}{l}\text { Carregosa, } \\
\text { Monique Santos \& } \\
\text { Faro, André }\end{array}$ & 2016 & $\begin{array}{l}\text { Conhecer o conceito de anabolizantes } \\
\text { e identificar benefícios e malefícios } \\
\text { do uso, segundo adolescentes. }\end{array}$ & $\begin{array}{l}\text { Os adolescentes se remetem à preocupação } \\
\text { de seu grupo quanto à aparência física ideal } \\
\text { e apresentam um discurso sobre os } \\
\text { anabolizantes voltado para a saúde, seja } \\
\text { através de uma falsa aparência saudável ou } \\
\text { dos prejuízos. }\end{array}$ \\
\hline $\begin{array}{l}\text { Freitas, Nayara et } \\
\text { al. }\end{array}$ & 2019 & $\begin{array}{l}\text { Avaliar o uso de EAA por praticantes } \\
\text { de musculação na cidade de Ji- } \\
\text { Paraná, Rondônia. }\end{array}$ & $\begin{array}{l}\text { Os EAA apresentam muitos efeitos } \\
\text { colaterais quando usados indevidamente. } \\
\text { Os profissionais de saúde devem pensar em } \\
\text { atitudes preventivas para que seu uso não } \\
\text { seja inadequado. }\end{array}$ \\
\hline Frati, Paola et al. & 2015 & $\begin{array}{l}\text { Revisar as tendências atuais do uso } \\
\text { indevido de drogas inteligentes e o } \\
\text { aprimoramento cognitivo em } \\
\text { comparação ao uso de EAA no } \\
\text { esporte. }\end{array}$ & $\begin{array}{l}\text { Há um mau uso e abuso dessas substâncias } \\
\text { no esporte e isso é feito sem a consciência } \\
\text { do "se pensar nos efeitos colaterais". }\end{array}$ \\
\hline $\begin{array}{l}\text { Cristofolini, Giseli } \\
\text { de Souza et al. }\end{array}$ & 2008 & $\begin{array}{l}\text { Analisar o conhecimento } \mathrm{dos} \\
\text { praticantes de musculação } \\
\text { academias sobre o assunto: EAA. }\end{array}$ & $\begin{array}{l}\text { Os praticantes de musculação mostram um } \\
\text { grau de conhecimento consideravelmente } \\
\text { satisfatório sobre EAA. }\end{array}$ \\
\hline $\begin{array}{l}\text { Machado, } \\
\text { Anderson Geraldo } \\
\& \text { Ribeiro, Paulo } \\
\text { César }\end{array}$ & 2004 & Melhor conhecimento sobre EAA. & $\begin{array}{l}\text { Em doses terapêuticas adequadas e sob } \\
\text { controle e supervisão de médicos, os EAA } \\
\text { causam poucos efeitos colaterais. O uso por } \\
\text { razão estética ou frívola, sempre em doses } \\
\text { elevadas (uso abusivo) traz consequências } \\
\text { graves. }\end{array}$ \\
\hline $\begin{array}{l}\text { Ribeiro, } \\
\text { Cesar }\end{array}$ & 2001 & $\begin{array}{l}\text { Considerações sobre o abuso de } \\
\text { esteroides anabolizantes e as razões } \\
\text { que levam os jovens e adultos a isto. }\end{array}$ & $\begin{array}{l}\text { É importante que os profissionais da saúde } \\
\text { que atendem os adolescentes estejam } \\
\text { atentos ao fato e questionem durante a } \\
\text { entrevista o uso destas substâncias. }\end{array}$ \\
\hline
\end{tabular}

\section{Considerações finais}

Desde que utilizados em doses terapêuticas e sob acompanhamento de profissionais de saúde, os EAA podem ser benéficos e auxiliar no tratamento de diversas patologias, pesando-se sempre clinicamente a relação risco-benefício. Por outro lado, há uma necessidade de políticas públicas de saúde que possam incentivar a promoção de uma maior conscientização por parte de profissionais de saúde e população em geral, de modo a guiar o estabelecimento e práticas que permitam o entendimento do contexto no qual esta classe terapêutica é apropriada, desde que sérios riscos à saúde associados ao uso indiscriminado destes disruptores endócrinos é relacionado à consideráveis taxas de morbidade e mortalidade. Neste mesmo sentido, cautela deve ser adotada, uma vez que estudos mostram sérios riscos à saúde associados ao uso de EAA, e sua toxicidade e risco geral pode variar de indivíduo para indivíduo.

\section{Referências}

1. Iriart JAB, Chaves JC, de Orleans RG. Culto ao corpo e uso de anabolizantes entre praticantes de musculação. Caderno de Saúde Pública. 2009; 25(4): 773-782. 
2. Cunha TS, Cunha NS, Moure MJCS, et al. Esteróides anabólicos androgênicos e sua relação com a prática desportiva. Revista Brasileira de Ciências Farmacêuticas. 2004; 40(2): 165-179.

3. Horwitz H, Andersen JT, Dalhoff KP. Health consequences of androgenic anabolic steroid use. Journal of Internal Medicine. 2019; 285: 333-340.

4. Carregosa MS, Faro A. O Significado dos Anabolizantes para os Adolescentes. Sociedade Brasileira de Psicologia. Temas Em Psicologia. 2016; 24(2[s.1.]): 519-532.

5. Rocha FL, Roque FR, de Oliveira EM. Esteróides anabolizantes: mecanismos de ação e efeitos sobre o sistema cardiovascular. O Mundo da Saúde. 2007; 31(4): 470-477.

6. Venâncio DP, Nobrega ACL, Tufik S, Mello MT. Avaliação Descritiva sobre o Uso de Esteróides Anabolizantes e seu Efeito sobre as Variáveis Bioquímicas e Neuroendócrinas em Indivíduos que Praticam Exercício Resistido. Revista Brasileira de Medicina do Esporte. 2010; 16(3): 191-195.

7. Freitas AC, Damião B, Alves DM, Ribeiro M, Fernandes GJM, Rossi Júnior WC, Esteves A. Efeitos dos anabolizantes sobre a densidade de neurônios dos núcleos da base. Rev Bras Med Esporte. 2017; 23(3): 213-216.

8. Franz F, Garcia PCR. Efeitos do esteroide anabolizante ao longo prazo e os benefícios da sua utilização associado à fisioterapia no desmame da ventilação mecânica de crianças com disfunção ventilatória. $\mathrm{V}$ Mostra de Pesquisa da Pós-graduação - PUCRS. 2010; 1155-1157.

9. Godoy IC, Pontes LS, Valentim T, et al. Uso clínico de esteroides anabolizantes em idosos sarcopênicos. Archives of Health Investigation. 2017; 6(2): 75-79.

10. González-Martí I, Fernández-Bustos JG, Contreras Jordán OR, et al. Muscle dysmorphia: detection of the use-abuse of anabolic androgenic steroids in a Spanish sample. Adicciones. 2018; 30(4): 243-250.

11. Ribeiro PCP. O uso indevido de substâncias: esteróides anabolizantes e energéticos. Adolescência Latinoamericana 2001; 2(2): 97-101.

12. Machado AG, Ribeiro PCP. Anabolizantes e seus Riscos. Adolescência \& Saúde 2004; 1(4): $20-22$.

13. Cristofolini GS, Borba PCR, Blunk Jr E, Liberali R. O padrão de conhecimento dos praticantes de musculação sobre esteróides anabolizantes. Revista Brasileira de Prescrição e Fisiologia do Exercício. 2008; 2(12): 699-714.

14. Frati P, Kyriakou C, Del Rio A, Marinelli E, Vergallo GM, Zaami S, Busardò FP. Smart Drugs and Synthetic Androgens for Cognitive and Physical Enhancement: Revolving Doors of Cosmetic Neurology. Current Neuropharmacology. 2015; 13(1): 5-11.

15. Freitas NCD, da Silva MMR, Bassoli BK, da Silva FC. O uso de esteróides androgênicoss anabolizantes por prticantes de musculação. South Amercian Journal of Basic Education, Technical and Technological. 2019; 6(2): 335-345.

16. Nunes ACCA, Bezerra KS, Batista SO, Vianna JF, Barbosa ED, Braga AO, Clemente Júnior WS, Fulco UL. Efeitos indiscriminado do uso de esteroides anabólicos androgênico no sistema cardiovascular. Braz J Develop 2020; 6(12): 101229-101240. 